\title{
Pengembangan Media Pembelajaran Interaktif Berbasis Etnomatematika Berbantu Macromedia Flash
}

\author{
Dimas Sofri Fikri Arif $^{1^{*}}$, Djoko Purnomo ${ }^{2}$, \& Sutrisno \\ ${ }^{1}$ Universitas PGRI Semarang, ${ }^{2}$ Universitas PGRI Semarang, ${ }^{3}$ Universitas PGRI Semarang
}

\section{INFO ARTICLES}

\section{Article History:}

Received: 01 Mei 2019

Revised: 15 Mei 2019

Approved: 05 Juni 2019

Publish Online: 26 Juni 2019

\section{KeyWords:}

Media interaktif, etnomatematika, macromedia flash

\section{c) (7) (2) \\ under a Creative} ShareAlike 4.0 International License.

\begin{abstract}
Abstrak: Penelitian ini bertujuan untuk mengembangkan media pembelajarann interaktif berbasis etnomatematika berbantu macromedia flash pada materi kubus dan balok SMP Kelas VIII. Rata-rata penilaian uji validasi materi diperoleh 4,60 (sangat baik) dan ahli media pembelajaran diperoleh 4,62 (sangat baik). Dilakukan uji keefektifan dengan postest. Dari analisis nilai postest dapat disimpulkan bahwa hasil belajar kelas eksperimen lebih baik dari kelas kontrol. Berdasarkan penelitian yang dilakukan dapat disimpulkan bahwa media pembelajaran interaktif berbasis etnomatematika berbantu macromedia flash pada materi kubus dan balok SMP kelas VIII yang dikembangkan valid dan efektif untuk digunakan sebagai media pembelajaran matematika pada materi kubus dan balok kelas VIII.

Abstract: This study aims to develop ethnomatematics-based interactive learning media aided by macromedia flash on cube and beam material in Class VIII Middle School. The average test material validation obtained 4.60 (very good) and learning media experts obtained 4.62 (very good). Test effectiveness with posttest. From the analysis of posttest values it can be concluded that the experimental class learning outcomes are better than the control class. Based on the research carried out, it can be concluded that the interactive learning media based on ethnomatematics assisted by macromedia flash on SMP and VIII cube and beam material which was developed validly and effectively was used as a learning media for mathematics in cube and beam material class VIII.
\end{abstract}

Correspondence Address: Jl. Sidodadi Timur No.24, Karangtempel, 50232, Indonesia; e-mail: dsofri@ yahoo.com

How to Cite (APA 6 ${ }^{\text {th }}$ Style): Arif, D.S.F., Purnomo, D., Sutrisno. (2019). Pengembangan Media Pembelajaran Interaktif Berbasis Etnomatematika Berbantu Macromedia Flash. JKPM (Jurnal Kajian Pendidikan Matematika), 4 (2): 89-100.

Copyright: Arif, (2019)

Competing Interests Disclosures: The authors declare that they have no significant competing financial, professional or personal interests that might have influenced the performance or presentation of the work described in this manuscript. 


\section{PENDAHULUAN}

Salah satu media pembelajaran yang memanfaatkan perkembangan teknologi yaitu media berbasis komputer. Pembelajaran menggunakan komputer sangat dinikmati oleh siswa, selain itu komputer juga dapat membuat pembelajaran menjadi lebih efektif dan efisien (Utama, Nilaswati, \& Vionanda, 2012). Media berbasis komputer merupakan media interaktif, yaitu media yang membawa pesan atau informasi kepada siswa dan sebagian di antaranya memproses pesan atau informasi yang diungkapkan oleh siswa (Arsyad, 2016).

Banyak program komputer yang digunakan untuk membantu dalam proses belajar mengajar, seperti microsoft powerpoint dan media lain yang dapat menjadi sarana komunikasi antara guru dan siswa. Menurut Andinny \& Lestari (2016), "Penggunaan media pembelajaran yang sesuai adalah salah satu usaha yang dilakukan oleh guru dalam mengembangkan potensi peserta didik." Salah satunya yaitu media pembelajaran interaktif yang dibuat dengan menggunakan Macromedia Flash. Macromedia Flash merupakan perangkat lunak yang dapat digunakan untuk membuat sebuah animasi (Utama, Nilaswati, \& Vionanda, 2012).

Materi kubus dan balok adalah salah satu materi yang terdapat dalam bab bangun ruang sisi datar yang dipelajari di jenjang SMP kelas VIII. Berdasarkan pengamatan yang dilakukan di SMP Negeri 1 Adiwerna Kabupaten Tegal pada tanggal 18 Juli 2018, Bapak Sutrisno, S.Pd. (salah satu guru matenatika) mengatakan bahwa pembelajaran materi kubus dan balok di SMP Negeri 1 Adiwerna Kabupaten Tegal masih menggunakan media sederhana seperti kerangka serta alat peraga bentuk kubus dan balok. Alat peraga tersebut hanya bisa diterapkan sebagai visualisasi pada sub materi karakteristik kubus, sedangkan materi kubus dan balok mencakup karakteristik, volume dan luas permukaan, sehingga siswa kesulitan dalam memahami konsep volume dan luas permukaan kubus dan balok serta hanya menghafal rumus untuk menyelesaikan permasalahan yang berkaitan dengan materi tersebut. Setiap kelas di SMP Negeri 1 Adiwerna Kabupaten Tegal sudah disediakan LCD proyektor yang belum dimanfaatkan untuk pembelajaran matematika khususnya dalam materi kubus dan balok.

Indonesia adalah salah satu negara yang memiliki keragaman budaya yang menjadi ciri khas bangsa. Rakyat Indonesia harus menghargai, mencintai dan melestarikan kekayaan budaya yang kita miliki. Melalui etnomatematika guru bisa memperkenalkan dan melestarikan budaya lokal di samping memberi pengajaran matematika.

Menurut D’Ambrosio (Haryanto, 2015)," etnomatematika adalah matematika yang digunakan oleh manusia atau sekelompok manusia di dalam budayanya." Tanpa disadari matematika terdapat di semua kegiatan manusia, yaitu dalam perdagangan, pertukangan, dan aspek kehidupan lainnya. Misalnya dalam pembelajaran materi kubus dan balok digunakan makanan-makanan tradisional berbentuk kubus dan balok untuk mengenalkan bentuk dan sifat dari kubus dan balok sehingga di samping siswa dikenalkan bentuk nyata kubus dan balok, siswa juga dapat menambah wawasan tentang budayanya. Oleh karena itu, dikembangkan media pembelajaran interaktif berbasis Etnomatematika berbantu Macromedia Flash pada materi kubus dan balok SMP kelas VIII. 


\section{METODE}

Penelitian ini adalah penelitian pengembangan media pembelajaran yang valid, dan efektif. Media pembelajaran yang dikategorikan valid yaitu jika media pada kriteria baik atau sangat baik dinilai oleh seorang ahli materi dan ahli media. Media pembelajaran yang dikategorikan efektif jika hasil belajar kelas yang menggunakan media tersebut lebih baik dari kelas yang tanpa menggunakan media tersebut. Prosedur pengembangan media pembelajaran dalam penelitian ini menggunakan model 4D menurut Thiagarajan (Sugiyono, 2015), yang merupakan singkatan dari Define, Desain, Development dan Dissemination. Tahap 1 yaitu define (pendefinisian), berisi kegiatan untuk menetapkan produk apa yang akan dikembangkan, beserta spesifikasinya. Kegiatan ini merupakan analisis kebutuhan yang dilakukan melalui penelitian dan studi literatur. Tahap ke 2 yaitu design (perancangan), berisi kegiatan untuk membuat rancangan terhadap produk yang telah ditetapkan pada tahap 1. Tahap ke 3 yaitu development (pengembangan), berisi kegiatan membuat rancangan menjadi produk dan menguji validitas produk secara berulang-ulang sampai dihasilkan produk sesuai dengan spesifikasi yang ditetapkan. Tahap ke 4 yaitu dissemination (diseminasi) berisi kegiatan menyebarluaskan produk yang telah teruji untuk dimanfaatkan orang lain.

\section{HASIL}

Fase Define (pendefinisian) yang berisi kegiatan untuk menetapkan produk yang akan dikembangkan dan spesifikasinya. Kegiatan ini berupa analisis kebutuhan yang dilakukan melalui penelitian dan studi literatur. Peneliti melakukan wawancara kepada Bapak Sutrisno, S.Pd. (salah satu guru matematika di SMP N 1 Adiwerna) pada tanggal 18 Juli 2018 untuk memperoleh informasi, diantaranya:

a. Pada pembelajaran bangun ruang sisi datar, khususnya kubus dan balok masih menggunakan media sederhana berupa alat peraga kubus dan balok.

b. Siswa mengalami kesulitan dalam memahami konsep luas permukaan dan volume kubus serta balok.

c. Fasilitas yang ada di kelas seperti LCD proyektor masih belum dimaksimalkan

d. Belum banyak media pembelajaran yang menghubungkan dengan budaya

Berdasarkan permasalahan tersebut, peneliti mengembangkan Media Pembelajaran Interaktif berbasis Etnomatematika berbantu Macromedia Flash pada Materi Kubus dan Balok SMP kelas VIII untuk mengatasi permasalahan tersebut. Media tersebut berisi materi yang berbasis etnomatematika dan dikemas dalam animasi, contoh soal serta kuis untuk siswa berlatih sehingga siswa mudah memahami materi tersebut.

Design (perancangan) berisi kegiatan untuk membuat rancangan terhadap produk yang telah ditetapkan.

a. Penyusunan materi

Pada tahap ini peneliti mengumpulkan materi tentang kubus dan balok di buku pelajaran matematika kelas VIII semester genap serta internet. Peneliti juga menambahkan etnomatematika sebagai dasar dalam pembuatan materi serta soal yang ada dalam media tersebut agar disamping siswa memahami materi, siswa juga mengetahui budaya-budaya yang ada di Indonesia yang terkonsep dalam media tersebut.

b. Mendesain produk 
Peneliti mendesain produk menggunakan aplikasi Macromedia Flash agar materi dapat lebih menarik dengan animasi yang dibuat menggunakan aplikasi tersebut. Pewarnaan background, tulisan, gambar dan animasi perlu diperhatikan agar media tersebut menarik dan mudah dipahami. Desain produk terbagi menjadi beberapa bagian. Berikut penjelasannya:

1) Halaman Awal

Halaman awal berisi tombol play. Setelah tombol play diklik kemudian langsung di arahkan ke halaman Menu.

2) Halaman Menu

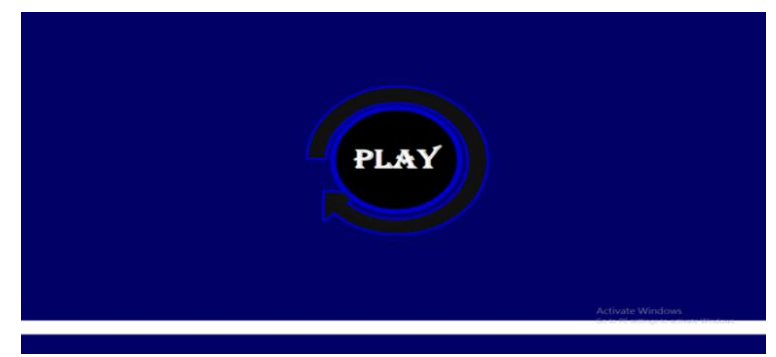

Gambar 1 Halaman Awal

Halaman Menu berisikan Tombol Kompetensi Dasar dan Indikator, Materi, Contoh, Profil, Quiz, Informasi Tombol serta Tombol Keluar

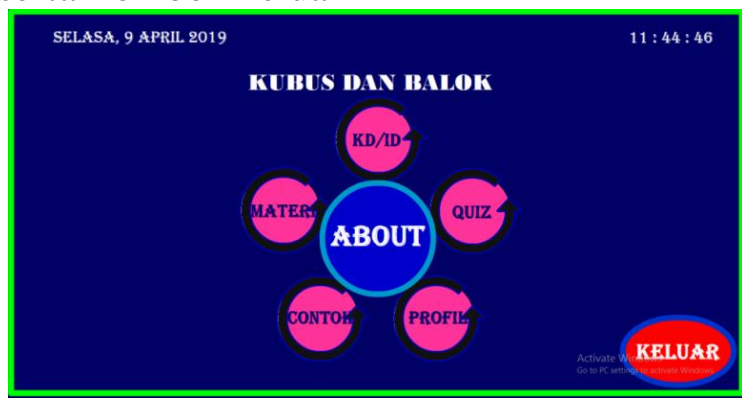

Gambar 2 Halaman Menu

3) Halaman Keterangan Tombol

Halaman Keterangan Tombol berisi keterangan setiap tombol yang ada dalam media ini. Sehingga pengguna dapat mengenal masing-masing fungsi tombol sebelum menggunakan media tersebut.

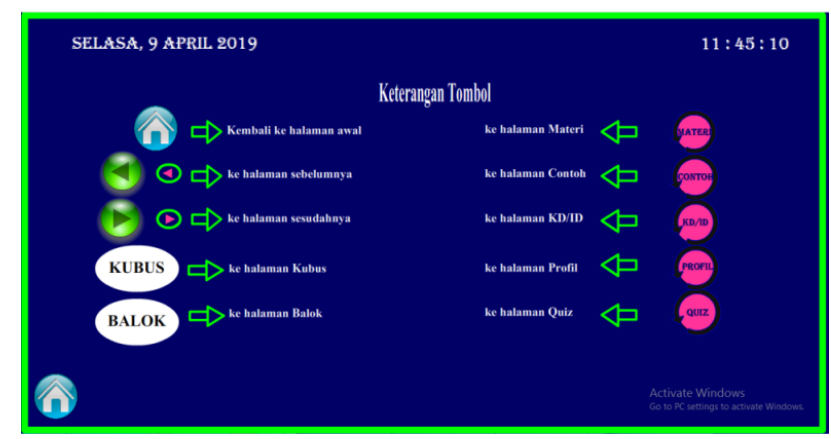

Gambar 3 Halaman Keterangan Tombol

4) Halaman Kompetensi Dasar dan Indikator

Halaman KD/ID berisikan informasi tentang Kompetensi yang akan dipelajari dan indikator yang akan dicapai. Sehingga siswa tahu apa yang akan dipelajari pada pembelajaran tersebut. 


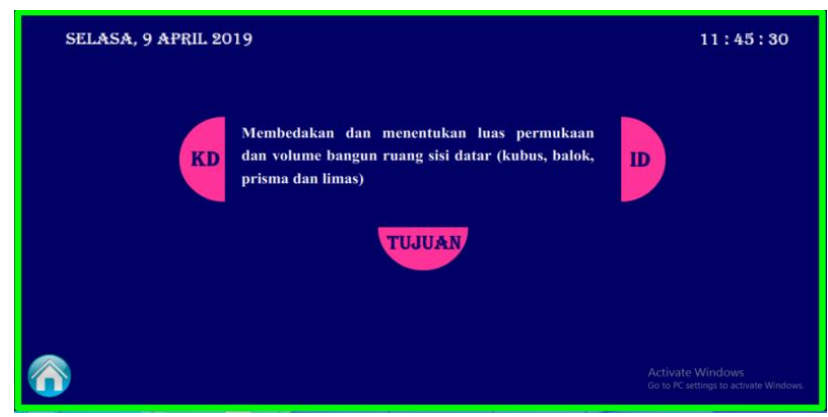

Gambar 4 Halaman KD/ID

5) Halaman Materi

Halaman Materi berisi materi kubus dan balok yaitu karakteristik, luas permukaan, volume kubus dan balok. Masing-masing materi divisualisasikan dengan animasi yang memudahkan siswa untuk memahami materi tersebut.

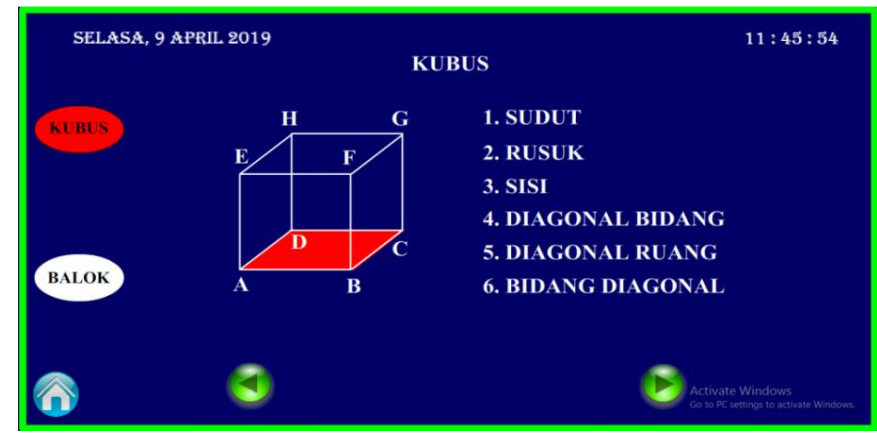

6) Halaman Contoh Soal

\section{Gambar 5 Halaman Materi}

Halaman contoh soal berisi contoh permasalahan dan penyelesaian yang berkaitan dengan materi kubus dan balok. Terdapat 4 contoh soal dalam media tersebut.

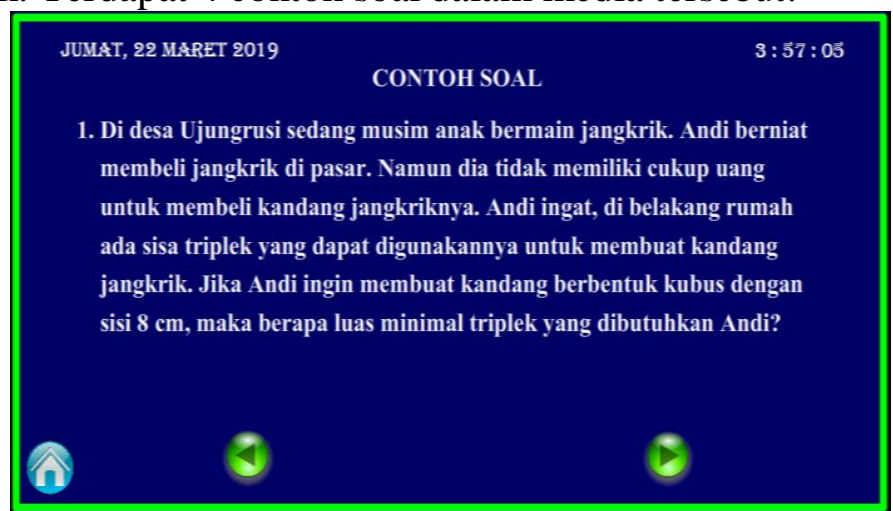

Gambar 6 Halaman Contoh Soal

7) Halaman Kuis

Halaman Kuis berisi latihan soal materi kubus dan balok. Terdapat 10 soal yang dapat langsung dikerjakan dan mengetahui ketuntasan dari pengerjaan soal tersebut 


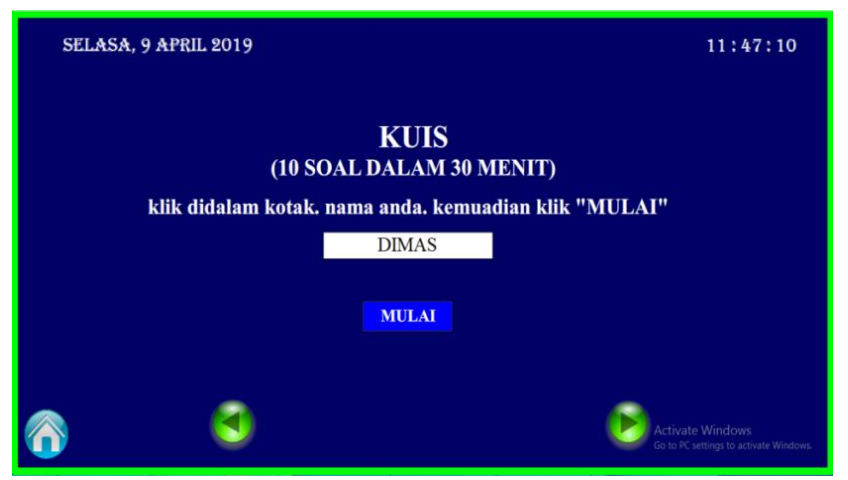

Gambar 7 Halaman Kuis

8) Halaman Profil

Halaman Profil berisi informasi tentang pembuat media ini.

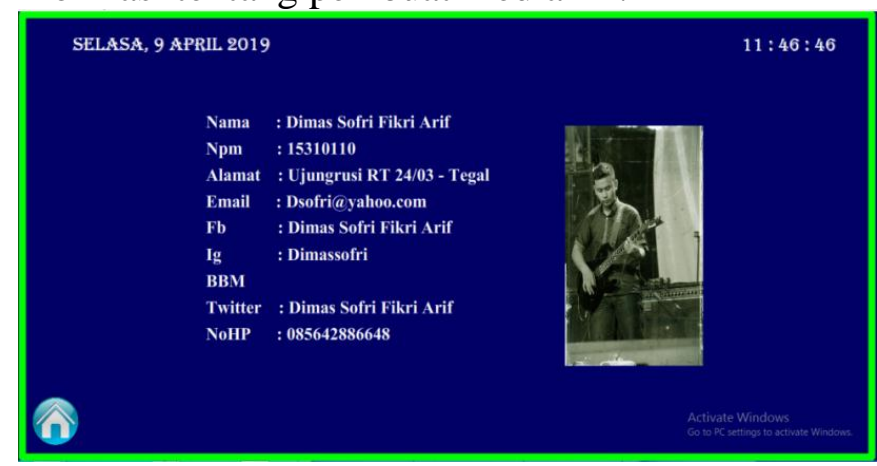

Gambar 8 Halaman Profil

c. Pembuatan contoh dan soal

Contoh soal sangat dibutuhkan agar siswa lebih memahami materi dan dapat mengaplikasikan materi ke dalam soal maupun kehidupan sehari-hari yang berkaitan dengan materi yang diajarkan. Maka dari itu, peneliti menyiapkan contoh soal yang dapat menambah pemahaman siswa setelah mempelajari materi tersebut.

Development (pengembangan), berisi kegiatan membuat rancangan menjadi produk dan menguji validitas produk secara berulang-ulang sampai dihasilkan produk sesuai dengan spesifikasi yang ditetapkan.

a. Pembuatan media

Setelah materi terkumpul dan desain telah ditentukan, selanjutnya peneliti membuat produk yang telah dirancang menggunakan aplikasi macromedia flash.

b. Validasi Ahli

Pada tahap ini peneliti menetukan ahli/validator untuk melakukan uji terhadap media tersebut yaitu ahli media dan ahli materi. Validasi ahli dibutuhkan untuk menilai kelayakan media tersebut. Validator yang dipilih yaitu ahli yang berkompeten dan mengerti pada bidangnya masing-masing. Penilaian dan saran yang diberikan oleh validator akan menjadi bahan untuk merevisi media tersebut agar menjadi lebih baik lagi. Berikut adalah nama validator dalam penelitian ini: 
Tabel 1 Daftar Nama Validator Media Pembelajaran

\begin{tabular}{llll}
\hline No & \multicolumn{1}{c}{ Nama } & \multicolumn{1}{c}{ Validator Ahli } & \multicolumn{1}{c}{ Keterangan } \\
\hline 1 & Muhammad Prayito, & Ahli Materi & Dosen Pendidikan \\
& Ahli Media & Matematika \\
& & & Universitas PGRI \\
& & Semarang \\
& & Dosen Pendidikan \\
2 & Aurora Nur Aini, & Ahli Materi & Matematika \\
& S.Si., M.Sc. & Ahli Media & Universitas PGRI \\
& & & Semarang \\
& & Dosen Pendidikan \\
3 & Sofri Rizka Amalia, & Ahli Materi & Matematika \\
& M.Pd. & Ahli Media & Universitas \\
& & & Peradaban Bumiayu \\
\hline
\end{tabular}

Angket validasi ahli berisi beberapa aspek penilaian yang memiliki Skor 5 : Sangat Setuju (SS), Skor 4 : Setuju (ST), Skor 3 : Ragu-ragu (RG), Skor 2 : Tidak Setuju (TS), Skor 1 : Sangat Tidak Setuju (STS). Hasil analisis validasi perangkat dijelaskan dalam Tabel 4.3 berikut

Tabel 2 Hasil Validasi Media Pembelajaran

\begin{tabular}{cccccc}
\hline No & \multicolumn{3}{c}{ Validator } & Rata-rata & Kriteria \\
\cline { 2 - 4 } & $\mathrm{V}_{1}$ & $\mathrm{~V}_{2}$ & $\mathrm{~V}_{3}$ & & \\
Ahli Media & 4 & 4,93 & 4,93 & 4,62 & Sangat baik \\
Ahli & 4 & 4,87 & 4,94 & 4,60 & Sangat baik \\
Materi & & & & & \\
\hline
\end{tabular}

Rata-rata penilaian dari validator adalah sangat baik serta kesimpulan dari semua ahli menyatakan Media pembelajaran interaktif berbasis etnomatematika berbantu Macromedia Flash pada materi kubus dan balok kelas VIII SMP layak diujicobakan di lapangan dengan revisi. Oleh karena itu media tersebut dinyatakan valid.

Untuk menguji keefektifan media tersebut dilakukan postest terhadap kelas kontrol dan kelas eksperimen. Hasil uji kesamaan rata-rata kelas kontrol dan eksperimen yaitu $t_{\text {hitung }}=2,662$, dengan derajat kebebasan untuk distribusi $\mathrm{t}_{1}$ adalah $\left(\mathrm{n}_{1}-1\right)=31$, $\mathrm{t}_{2}$ adalah $\left(\mathrm{n}_{2}-1\right)=31$, peluang $(1-\alpha)$ dengan $\alpha=5 \%$ diperoleh $t_{(0,95)(31)}=1,698, w_{1}=4,127, w_{2}=17,264$. Kriteria pengujian yang berlaku adalah terima $H_{0}$ jika: $\mathrm{t}$ hitung $<\frac{w_{1} t_{1}+w_{2} t_{2}}{w_{1}+w_{2}}$. Karena $\mathrm{t}$ hitung $=2,662>1,698$ maka $H_{0}$ ditolak, jadi dapat disimpulkan bahwa rataan nilai tes dari kelas yang diajar menggunakan media interaktif berbasis etnomatematika lebih dari rataan nilai tes kelas yang diajar tanpa menggunakan media interaktif berbasis etnomatematika.

Dissemination (diseminasi) berisi kegiatan menyebarluaskan produk yang telah teruji untuk dimanfaatkan orang lain. Setelah produk tersebut selesai diujicobakan dan dinyatakan valid dan efektif, selanjutnya produk tersebut disebarluaskan kepada guru matematika kelas 8, dan siswa kelas 8A dan 8B SMP Negeri 1 Adiwerna.

\section{PEMBAHASAN}


Research and Development $(R \& D)$ atau penelitian dan pengembangan adalah suatu proses atau langkah-langkah untuk mengembangkan suatu produk baru atau menyempurnakan produk yang telah ada, yang dapat dipertanggungjawabkan. Produk tersebut tidak selalu berbentuk benda atau perangkat keras (hardware), seperti buku, modul, alat bantu pembelajaran di kelas atau di laboratorium, tetapi bisa juga berbentuk perangkat lunak (software), seperti program komputer untuk pengolahan data, pembelajaran di kelas, perpustakaan atau laboratorium, ataupun model-model pendidikan, pembelajaran, pelatihan, evaluasi, manajemen, dan lain-lain (Sukmadinata, 2012). Metode penelitian pengembangan atau dalam bahasa inggrisnya Research and Development $(R \& D)$ adalah metode penelitian yang digunakan untuk menghasilkan produk tertentu, dan menguji keefektifan produk tersebut (Sugiyono, 2015). Dengan perangkat pembelajaran yang valid, akan menghasilkan suatu sistem perangkat yang dapat dijadikan alternatif dalam pelaksanaan pembelajaran, oleh karena itu suatu perangkat pembelajaran yang baik adalah perangkat yang harus dikonsultasikan pada para ahli dibidangnya sehingga menghasilkan perangkat yang sesuai dengan kriteria, baru setelah itu dapat diimplementasikan dalam kegiatan belajar mengajar (Zuhri, Purwosetiyono, \& Sutrisno, 2014). Peneliti melakukan penelitian dan pengembangan dengan membuat produk media pembelajaran interaktif yang valid dan efektif.

One of the factors that determine the success of mathematics learning is the learning media used (Widodo \& Wahyudin, 2018). Educational media and multimedia technology are the channels of transmitting information to learners' and are also those gadgets, and machines that are needed in transmitting information to learners (Omodara \& Adu, 2014). In learning communication, learning media is needed to improve the effectiveness of learning achievement goals (Widodo \& Wahyudin, 2018).

Media merupakan salah satu faktor yang mendukung keberhasilan proses pembelajaran di sekolah karena dapat membantu proses penyampaian informasi dari guru kepada siswa atau sebaliknya (Arda, Saehana, \& Darsikin, 2015). The role of the interactive multimedia courseware in the classroom is not to replace traditional educational methods, it does act as an enhancement for teaching students to think critically, communicate creatively and solve problems in analytical way especially in mathematics (Ussher, Damoah, Ansong, \& Quarshie, 2014). Menurut Prasetyo (dalam Widodo \& Wahyudin, 2018), Learning media is a tools or equipment to implement processes that enable educators and learners to carry out learning activities. Educational media and technology can be defined as all means of communication like prints, graphics, animations, audios and audiovisuals (Omodara \& Adu, 2014).

Menurut Association of Education and Communication Technologi (dalam Arsyad, 2016), media sebagai segala bentuk dan saluran yang digunakan untuk menyampaikan pesan atau informasi. Menurut Thomas (dalam Omodara \& Adu, 2014) in education, media are the symbol systems that teachers and learners utilise in representing knowledge and technologies are the tools that allow them to share their knowledge representations with others. Salah satu media yang dapat digunakan dalam pembelajaran yaitu media komputer. Pembelajaran menggunakan komputer sangat dinikmati oleh siswa, selain itu komputer juga dapat membuat pembelajaran menjadi lebih efektif dan efisien (Utama, Nilaswati, \& Vionanda, 2012). The ongoing evolution of digital media and the possibilities of communication and access to information which they offer draw particular attention to the need to develop citizens' effective, responsible and critical behavior not only as consumers, but also as communicators and media message producers (Mota, Festas, 
\& Seixas, 2016). Media berbasis komputer merupakan media interaktif, yaitu media yang membawa pesan atau informasi kepada siswa dan sebagian di antaranya memproses pesan atau informasi yang diungkapkan oleh siswa (Arsyad, 2016).

Media pembelajaran interaktif adalah alat yang dirancang untuk memperjelas penyajian pesan, informasi dan dapat mengatasi keterbatasan indera, ruang, waktu dan objek atau benda yang terlalu besar atau benda yang terlalu kecil yang tidak tampak oleh indera dapat disajikan dengan bantuan mikroskop, film, slide, atau gambar (Zulhelmi, Adlim, \& Mahidin, 2017). Multi-media should be made available to lecturers and students of Mass Communication and also provide adequate power to run the system. There should be enlightenment on the importance of interactive media for teaching and learning in tertiary institutions. These facilities should be made available in all Mass Communication Departmentsfor effective communication education (Ngonso, Egielewa, \& Nyong, 2018). Media pembelajaran interaktif atau multimedia interaktif mampu meningkatkan konsep (Kurniawati \& Nita, 2018). Maka dari itu peneliti mengembangkan sebuah media sebagai alat penyampaian pesan yang dapat membuat pembelajaran lebih efektif dan efisien serta dapat meningkatkan konsep siswa sehingga siswa lebih mudah dalam memahami konsep materi yang dipelajari khususnya pada materi luas permukaan dan volume kubus serta balok.

Etnomatematika adalah matematika dalam budaya (Hardiarti, Aplikasi Bangun Datar Segiempat Pada Candi Muaro Jambi, 2017). Etnomatematika merupakan matematika yang tumbuh dan berkembang dalam kebudayaan masyarakat tertentu (Laurens, 2016). Menurut D’Ambrosio (dalam Haryanto, 2015), etnomatematika adalah matematika yang digunakan oleh manusia atau sekelompok manusia di dalam budayanya. Sadar atau tidak sadar semua kegiatan manusia di dunia ini dilakukan atas dasar perhitungan yang tepat sesuai dengan kondisi alam tempat manusia tersebut tinggal. Etnomatematika muncul dari proses kehidupan masyarakat yang berkaitan langsung dengan matematika, misalnya bilangan dan sistem bilangan, geometri, dan lain sebagainya (Dahlan \& Permatasari, 2018). Menurut Barton (dalam Nuh \& Dardiri, 2016) etnomatematika merupakan kajian yang meneliti cara sekelompok orang dari budaya tertetu dalam memahami, mengekspresikan dan menggunakan konsep-konsep serta praktik-praktik kebudayaannya yang digambarkan sebagai sesuatu yang matematis. Peneliti menggunakan etnomatematika sebagai dasar dalam penyampaian materi, karena disamping siswa lebih mudah memahami permasalahan yang ada di sekitar kita, siswa juga dapat memperoleh pengetahuan tentang budaya yang ada di sekitar kita.

Macromedia Flash adalah sebuah software animasi yang sekarang menjadi software favorit para web designer untuk membuat webnya terlihat dinamis dan lebih atraktif. Bahkan sekarang Flash digunakan untuk berbagai keperluan, diantaranya untuk presentasi, proposal modern, e-card, game, dan lain-lain. Seiring dengan perkembangan zaman maka Flash Pro 8 disesuaikan sesuai kebutuhan akan pembuatan sebuah aplikasi web di samping pembuatan animasi (Ariyanto, Tsalatsa, \& Sutrisno, 2015). Penggunaan Macromedia Flash sebagai alat bantu pembuatan media dikarenakan fasilitas dalam aplikasi tersebut mampu untuk membuat animasi sehingga dapat menjadikan pembelajaran lebih nyata dan dapat menjadikan siswa lebih mudah dalam mempelajari materi yang disampaikan.

Berdasarkan penelitian dan pengembangan yang dilakukan oleh Utama dkk (2012) di SMA Payukumbuh, nilai rata-rata pada kelas eksperimen yaitu kelas yang diajar menggunakan metode $C A I$ (Computer Assisted Instruction) dan media pemmbelajaran berbantu Software Macromedia Flash adalah 78,09 , sedangkan kelas konvensional memiliki rata-rata nilai 74,88. Hal ini menunjukan bahwa rata-rata 
kelas eksperimen lebih baik dari kelas kontrol. Jadi dapat disimpulkan penggunaan media berbantu macromedia flash lebih efektif dibandingkan tanpa menggunakan media pembelajaran tersebut.

Penelitian ini adalah pengembangan media pembelajaran interaktif berbasis etnomatematika berbantu Macromedia Flash pada materi kubus dan balok kelas VIII SMP yang valid dan efektif. Hasil penelitian menunjukkan bahwa (1) rata-rata penilaian dari validator adalah sangat baik serta kesimpulan dari semua ahli menyatakan Media pembelajaran interaktif berbasis etnomatematika berbantu Macromedia Flash pada materi kubus dan balok kelas VIII SMP dinyatakan valid, (2) rataan nilai tes dari kelas yang diajar menggunakan media interaktif berbasis etnomatematika lebih dari rataan nilai tes kelas yang diajar tanpa menggunakan media interaktif.

Pengembangan media pembelajaran interaktif berbasis etnomatematika berbantu Macromedia Flash pada materi kubus dan balok SMP kelas VIII merupakan salah satu usaha peneliti untuk memudahkan guru dalam menyampaikan materi kubus dan balok sehingga siswa lebih mudah dalam memahami konsep luas permukaan dan volume kubus dan balok, serta seiring dengan perkembangan zaman yang menuntut untuk memanfaatkan teknologi sehingga dengan adanya media ini dapat memanfaatkan fasilitas yang ada khususnya di SMP Negeri 1 Adiwerna. Tahapan yang dilalui untuk mengembangkan media tersebut dijelaskan sebagai berikut.

1. Define (pendefinisian), berisi kegiatan untuk menetapkan produk apa yang akan dikembangkan, beserta spesifikasinya. Kegiatan ini merupakan analisis kebutuhan yang dilakukan melalui penelitian dan studi literatur yang dilakukan di SMP Negeri 1 Adiwerna.

2. Design (perancangan), berisi kegiatan untuk membuat rancangan media pembelajaran interaktif berbasis etnomatematika berbantu Macromedia Flash pada materi kubus dan balok SMP kelas VIII.

3. Development (pengembangan), berisi kegiatan membuat rancangan menjadi produk dan menguji validitas produk secara berulang-ulang sampai dihasilkan produk yang valid dan efektiv.

4. Dissemination (diseminasi) berisi kegiatan menyebarluaskan produk yang telah teruji untuk dimanfaatkan orang lain khususnya di SMP Negeri 1 Adiwerna.

\section{SIMPULAN}

Berdasarkan uji validasi ahli materi dan ahli media serta uji efektifitas yang dilakukan di SMP Negeri 1 Adiwerna, dapat disimpulkan Media pembelajaran interaktif berbasis etnomatematika berbantu macromedia flash pada materi kubus dan balok valid dan efektif.

\section{UCAPAN TERIMA KASIH}

Terimakasih kepada Bapak Uripto, S.Pd.,M.Pd. yang telah mengijinkan dilakukannya penelitian di SMP Negeri 1 Adiwerna. Kepada Bapak Ibu dan saudara-saudaraku yang telah mendukung dan mendoakan suksesnya penelitian ini. Terimakasih juga kepada pihak yang membantu yang tidak bisa saya sebut satu per satu.

\section{DAFTAR PUSTAKA}


Ariyanto, L., Tsalatsa, N., \& Sutrisno. (2015). Pengembangan Bahan Ajar Macromedia Flash Pro 8. Semarang: Mediamatematika.

Arsyad, A. (2016). Media Pembelajaran. Jakarta: PT Rajagrafinda Persada.

Andinny,Y., \& Lestari, I. (2016). Pengaruh Pembelajaran Multimedia terhadap Hasil Belajar Matematika. JKPM (Jurnal Kajian Pendidikan Matematika), 1 (2): 169-179.

Budiyono. (2011). Penilaian Hasil Belajar. Surakarta: Universitas Sebelas Maret.

Dahlan, J. A., \& Permatasari, R. (2018). Pengembangan Bahan Ajar berbasis Etnomatematika dalam Pembelajaran Matematika Sekolah Menengah Pertama. Jurnal Nasional Pendidikan Matematika , II, 133.

Hardiarti, S. (2017). Aplikasi Bangun Datar Segiempat Pada Candi Muaro Jambi. Aksioma , II, 99.

Haryanto. (2015). Etnomatematika pada Noken Masyarakat Papua. Seminar Nasional Matematika dan Pendidikan Matematika, 1178.

Kurniawati, I. D., \& Nita, S. (2018). Media Pembelajaran Berbasis Multimedia Interaktif untuk Meningkatkan Pemahaman Konsep Mahasiswa. DoubleClick , II, 68.

Laurens, T. (2016). Analisis Etnomatematika dan Pernerapannya dalam Meningkatkan Kualitas Pembelajaran. Lemma , 86.

Mota, A. P., Festas, M. I., \& Seixas, A. M. (2016). Digital media and the challenges for media education. Applied Technologies and Innovations, XII (2), 43.

Ngonso, Egielewa, \& Nyong. (2018). Influence of Interactive Media on Communication Education in Nigeria. Global Media Journal , XVI, 1.

Nuh, Z., \& Dardiri. (2016). Etnomatematika dalam Sistem Pembilangan pada Masyarakat Melayu Riau. Jurnal Penelitian Sosial Kebudayaan .

Omodara, \& Adu. (2014). Relevance of Educational Media and Multimedia Technology for Effective Service Delivery in Teaching and Learning Processes. Journal of Research \& Method in Education (IOSR-JRME) , IV (2), 48.

Sugiyono. (2015). Metode Penelitian \& Pengembangan. Bandung: Alfabeta.

Sukmadinata, N. S. (2012). Metode Penelitian Pendidikan. Bandung: PT Remaja Rosdakarya.

Ussher, J., Damoah, D., Ansong, E., \& Quarshie, H. (2014). The Effectiveness of Interative Multimedia Courseware as Instructional Medium for Teaching. British Journal of Education , II, 36-47.

Utama, N. P., Nilawasti, \& Vionanda, D. (2012). Penggunaan Macromedia Flash 8 pada Pembelajaran Dimensi Tiga. Jurnal Pendidikan Matematika , I, 51-59.

Widodo, S. A., \& Wahyudin. (2018). Selection of Learning Media Mathematics for Junior School Students. The Turkish Online Journal of Educational Technology, XVII (1), 154.

Zuhri, M. S., Purwosetiyono, F. X., \& Sutrisno. (2014). Pengembangan Desain Alata Peraga Matematika berbasi E-Learning untuk Membentuk Kreatifitas Mahasiswa pada Mata Kuliah Workshop. AKSIOMA, V, 31-41.

Zulhelmi, Adlim, \& Mahidin. (2017). Pengaruh Media Pembelajaran Interaktif terhadap Peningkatan Keterampilan Berpikir Kritis Siswa. Jurnal Pendidikan Sains Indonesia , V, 73. 